\title{
LIDIA BERSZÁN*
}

\section{CHANCES OF COPING WITH HAVING DISABLED CHILDREN FOR FAMILIES IN RUMANIA}

(Received: 29 February 2008; accepted: 19 November 2008)

\begin{abstract}
Most studies deal with the way of how the hardships and stress aroused by the deficiency affect the family, the family relations and roles. However, some families having children with disabilities can face their situation due to their personality resources, their environment or with the help of social services. The article presents the results of a research on the coping strategies of parents with disabled children. The sample consists of 400 Rumanian families who brought up a disabled person aged 0 to 23 . The primary intention of the research was to provide as much information as possible about the families having disabled children, based on which it can be explored how they fight against the situation of life changed by the deficiency. The other aim of the research was to explore the situation of the families living with deficiency through examining the risk and resiliency factors, and to investigate how those families can find those supportive possibilities in their immediate circumstances, in the supplies provided by the supply-system and in their own personalities which make it possible for them to stay balanced in spite of the problems. This paper is looking for protective factors and solutions, which are helpful for parents in finding successful coping strategies. It also examines risk factors, which usually lead to a lack of balance in the family life and makes coping difficult.
\end{abstract}

Keywords: adaptation approach, coping strategies, risk and resiliency factors, criteria of successful coping, the coping profile

Eine rumänische Untersuchung über die Chancen für eine erfolgreiche Auseinandersetzung mit Behinderung: In der Mehrzahl der Studien geht es darum, wie sich die Probleme und der Stress, die sich aus einer Behinderung ergeben, auf die Familie, auf familiäre Beziehungen und Rollen auswirken. Ein Teil der Familien, die ein behindertes Kind erziehen, kann

* Lidia Berszán, Social Work Department, Babeş-Bolyai University, B.-ul 21 Decembrie 1989 nr. 128-130, R-400604 Cluj-Napoca, Rumania, lberszan@yahoo.com. 
sich auf die durch die Behinderung entstandene Situation einlassen und dabei die Unterstützungsmöglichkeiten nutzen, die ihnen personelle Ressourcen, die unmittelbare Umgebung und vom Versorgungssystem bereitgestellte Dienstleistungen bieten. Die Studie stellt die Ergebnisse einer in Rumänien durchgeführten Untersuchung über die Auseinandersetzung mit Behinderung vor. Die Stichprobe besteht aus 400 Familien, die ein behindertes Kind im Alter zwischen 0 und 23 Jahren haben. Vorrangiges Ziel der Untersuchung ist es, möglichst viele Informationen über diese Familien bereitzustellen, aufgrund deren deutlich wird, wie die Familien sich mit der durch die Behinderung veränderten Lebenssituation auseinander setzen. Ein weiteres Ziel der Studie ist die Erforschung der Situation und der Lebensführung dieser Familien mit Hilfe der Untersuchung der Risiken und der Resilienzfaktoren. Die Studie sucht nach den unterstützenden Faktoren und Bewältigungsstrategien, die den Familien am besten bei der Auseinandersetzung helfen, und versucht Risikofaktoren aufzudecken, die mit hoher Wahrscheinlichkeit und Häufigkeit zu einer Destabilisierung des Gleichgewichts führen.

Schlüsselbegriffe: Adaptation, Auseinandersetzung-Strategien, Risiko, Resilienz, Kriterien einer erfolgreichen Auseinandersetzung, Auseinandersetzungs-Profil

In the last four decades there has been intense research in the field of the quality of life and problems of families taking care of disabled children or adults. Methodologically the research of this field is a complex issue: which method makes the consequences resulting from the deficiency measurable; what kind of questions (and who) can be asked in order to understand the inner and outer relational system of the family; what is the aim of the research? A considerable part of the research is statistical in character: it makes the data concerning financial situation, degree of supply, education, etc., expressible in numbers and comparable. The effects of the deficiency on the family relations, on the social status and disposition of the family members, on the parents' coping capacities (coping mechanism), and the parameters of the chances of integration for those living with a deficiency are more difficult to research, but there exist similar researches. These researches also have many branches, but based on their orientation two directions can still be determined.

The problem-oriented approach wants to see what kind of hardships can result from the fact that a disabled child is born into a family, or a family member becomes handicapped. It investigates the initial shock effect aroused by the diagnosis, the distress effect generated by the latter, the changes in the parents' career and financial situation, the cultural and the social impacts which are felt in the given society in connection with the fact of the deficiency.

The adaptation approach tries to reveal how the family is coping with the changed situation, what kind of sources the family mobilises, and what solutions the family finds. This approach investigates the sources available in the parents' personality, their social background and environment, their relation network, their financial and job status, which could serve as a 'recipe' for creating a successful adaptation model. They have to learn first of all how to be able to attune the changing in manifestation of worry and anxiety in the family, according to the disability problem. 


\section{Former investigations - the analysis of the successful cases}

Most of the studies deal with the way of how the hardships and stress aroused by the deficiency affect the family, the family relations and roles. The researches say little about the causes and effects of positive adaptation, about the parents who have become more mature in their personality and in their relationship with their spouse, about the brothers and sisters having wider perspective, and about what it means in connection to the other members of the family if a family member can adapt in a positive way. The majority of the researches bring the message that those families are successful in adaptation whose education and financial situation is above the average level, whose marriage is good, who have strong bonds of brotherhood and sisterhood, and whose formal and informal social support is high. The obvious conclusion is that the positive cognitive adaptation (acceptance) is best helped by 'parent-to-parent help' programs. Those cases where the opportunities are modest, but still the families find the right attitude and develop their own lifestyle are less dealt with. It means positive adaptation when the parents reach the point where they can give up self-blame and do not ask the question any more: 'why me?' Instead they ask the question: 'can something good come out of this situation?', and 'what have we understood, learned, or what could we learn?' (SINGER 2002, 150). They can find the way of how the family can reach any favourable results on both a cognitive and an emotional level in that changed situation.

The researches of SANDERSON \& CRAWLEY (1982) investigated the cases of successful adaptation in the USA. They realised that the considerable majority of these families belong to the middle-class claiming to have conservative values: married couples, two-parent families, where the mother stays home with the children, religious people, involved in church activities or in parental committee activities. The parents are a little bit older than the parents of the healthy children of a similar age, and they practically do not have any bread-and-butter worries. Their education cannot be considered high compared to the families with similar parameters. The mother is the number one provider. The researches found negative correlation between the gravity of the deficiency and the acceptance: the more serious the child's deficiency, the less the parents can accept it and develop a balanced everyday life. This negative correlation could be demonstrated in each case where the child's state made the parent-child communication troubled or impossible (autism, or in cases where the basic diagnosis was accompanied by autistic behaviour). The more serious the child's biological vulnerability, his or her developmental delay is, the less the ability of accepting the situation is.

The research performed by Yau and Li-Tsang in Asia (LI-TSANG et al. 2001, 64) studied the way in which the families succeed in finding the balance and the positive attitude, how they are capable of that, what makes them find joy in their disabled children, how is it possible that they experience cohesion, that is, they experience that they get closer to each other in their relationships during the difficult periods. How come that they have many special needs and still they do not consider their children handicapped?

Yau and Li-Tsang have found that the families who have found the positive balance are characterised by the following facts: the parents are highly educated, their 
financial status is middle or good, their personality is balanced, they are optimistic, they have realistic expectations concerning their children and the specialists working with them, their relation network is strong. In the Asian pattern they have not found a negative correlation between the gravity of the deficiency and the acceptance. However, the number one provider is the mother here as well.

TAYLOR (1998) selected 6,000 consulted persons from the registry of the National Organization on Disability (USA) and on this representative pattern investigated the disability effects on the family. He studied the quality of life in the cases of disabled adults. He found that one third of them are satisfied with their quality of life. From those who wanted to work, $76 \%$ were unemployed $(4.9 \%$ of the national percentage). From those consulted who did not live at home $6 \%$ were able to choose their roommate, and $3 \%$ could wear the clothes they wanted every day. In the case of those who stayed at home, $80-85 \%$ of the parents were satisfied with the special education or activities which their adult child could be part of. The results of the investigation was summed up in the following way: the parents' capacity of coping with the deficiency is not so much affected by the gravity, the type of the deficiency or by the family-structure, as by the provocative or self destroying attitude of the child or adult living with the deficiency and by the bad financial state of the family.

BÁNFALVY (1996) in his research 'Quality of life '95' studied the quality of life in the case of 1,700 adults with mental deficiency, concerning their lifestyle, their state of supply and their social relations. He found that considering the lifestyle and the quality of life the characteristics resulting from the deficiency and the sociological ones exist and have an intertwined effect. The disabled children and young people born into families with higher social status had better chances of getting higher in society: they are more educated; they learn a profession and get a job in a higher proportion. However, the integration into the community and the family is better in the case of children whose parents have a lower social status, where the simpler environment and the family milieu with a smaller challenge prove to be more receptive and supportive.

M. Berg in 1995 developed the way in which the coping strategy of a family can be studied. This is a qualitative inductive analytical method which has been tested in several Western European countries. Berg was the first who studied the special characteristics of families who bring up handicapped children. Based on the gathered information and his previous experience he built up a hypothesis, then he put together a list of questions which he asked from parents who adapted successfully. The answers collected from the families cancelled or supported the previously built hypothesis based on the information.

When selecting the families he considered the following selective criteria:

- Those specialists who worked directly with the child and the parents - the early development team, social worker, therapist, psychologist - thought that the parents had accepted the child's deficiency.

- They were active in the parents' group, or in the interest enforcing organisation.

- Natural parents (not foster or adoptive) parents.

- The earlier the deficiency is identified, the earlier it is possible to intervene in the development of the child. 
He studied the coping mechanism of the parents along the following dimensions: attitudes, social values and help seeking behaviour. The positive view of life was a characteristic. 7 out of 10 parents declare that their scale of values has changed under the influence of the deficiency, the material values and career have lost some of their significance, and the relationships have been upgraded. They consider themselves family people; they have been consciously striving to put the family at the top of their priority list all their life. The fear of the future is present in the case of each family, despite that they try to focus their energy on the present, not brooding over the past, restraining anxiety because of the future. Half of the parents learned a lot about the child's problem, they felt this important. All of them admit that the children need to be taught-educated not only looked after. Each consulted parent has a common activity with the child outside the activities which belong to looking after him or her. Disabled children also need to be taught to express their emotions and feelings and to decrease the dependence on parents.

Their help seeking attitude is characterised by the fact that they all highly value realistic information and professional help. They think it is important to have discussions with specialists and to cooperate with them especially in the early, acceptance period. They believe it important to belong to a group, and to do something as well for those living with deficiencies. Even if the group does not directly help the child, if it supports the parent that is good for the child, too, so this is a 'no waste of time'. The parents with similar situations have the best influence on them during the acceptance period. They consider it important to help other parents who have disabled children. They are satisfied with the parent group they belong to.

\section{Rumanian research about the criteria for successfully fighting against deficiency (2003-2006)}

The author considers the ecological model built by Bronfenbrenner the most suitable theoretical basis for the Rumanian research of the quality of life among families having disabled children. According to the interactive point of view of the ecological model we are never passive participants of our environment, constant action-reaction effects assert themselves, we are continuously balancing between the risk factors causing us problems, challenges or even stress, and the protective factors being effective in our personality and environment. These effects always filter through the cognitive, emotional, physical and social behaviour, manifestation, but they also depend on the actual stage of development of the individual or family (BRONFENBRENNER 1979; FRASER 2004). The definition of the concepts of risk and resiliency in this model: A risk factor is every biogenetic, psychosocial, environmental or economical harming factor that hinders, slows down or harms the individual's well-being, development, independent and reasonable possibilities of living. A resiliency factor is every effect that activates and supports such sources of power that make it possible that in spite of the risk, or compensating it, the balance of the situation be preserved, the existence of the indi- 
vidual does not become impossible, his or her development does not take a pathological or deviant direction.

The primary intention of the research was to provide as much information as possible about the families having disabled children, based on which it can be explored how they fight against the situation of life changed by the deficiency.

When designing the research the author's starting point was the hypothesis that there must be common problems that are characteristic of all the cases of the families having disabled children. Some families can find those supportive possibilities in their immediate circumstances, in the supplies provided by the supply-system and in their own personalities which make it possible for them to stay balanced in spite of the problems. Supportive factors and solutions that can help the best, that work the best, and those risk factors which most probably and most often cause the unbalance are searched for.

The aim of the research is to explore the situation of the families living with deficiency through examining the risk and resiliency factors. The study of these is important because we do not know very well how they live, and it would be important to know how the supply-system could help, in what way it should adjust to their demands and needs.

The research model consists altogether of 400 families who live in 108 localities of 9 counties. There exists a national record of the number of disabled children in each county, but there is no available record or database concerning the breakdown by the type of locality, by the parents' profession, or by other data about the family. The model could also be given prominence based on the breakdown by counties or the degree of deficiency in order to make it more representative.

The components of the analysis are families whose children have been placed into a deficiency category and kept on record by the Rumanian Diagnose Committee. Because of their dependency not only those under the age of 18 are put here. ${ }^{1}$ (But the research model only included those handicapped individuals above the age of 18 who also have mental deficiency).

\section{Table 1}

Breakdown by the type of the child's deficiency $(\mathrm{N}=400)$

\begin{tabular}{lc}
\hline The type and degree of the deficiency & Percentage (\%) \\
\hline Cumulative deficiency & 54.0 \\
Limitation of motion & 19.0 \\
Mental deficiency & 12.3 \\
Organoleptic deficiency & 9.8 \\
Other & 5.0 \\
Altogether & 100.0 \\
\hline
\end{tabular}

\footnotetext{
${ }^{1}$ See the research performed by Li-Tsang who studied the coping strategies of families having disabled children between the ages of 6-28 (LI-TSANG et al. 2001, 63). The percentage of disabled 'children' above the age of 18 is $5.5 \%$ in the Rumanian research model.
} 
Though the questions are for one family member, they extend to all of the family members who live in the same household. The structure of the family, its financial situation, its social status, the attitude of each family member concerning the deficiency, the possibilities and habits for relaxation are studied. The author considers the family a suitable component for analysis, and not only the mother or one of the parents, because according to system theory the deficiency of one family member has an effect on all of the family members; however, taking care of him or her and his or her adaptation is their common task.

The data collection method was a questionnaire consisting of 80 questions referring to the quality of life and lifestyle, ${ }^{2}$ which were asked in the families' home by the interviewers. One emphasised goal of the research was to try and reveal the secret of how one can successfully cope with the lifestyle and spiritual problems aroused by the deficiency. The operational criteria used in the present study have been taken from the analysis described by BERG et al. (2004).

The following coping profile emerges:

- The successfully coping parents: 44 mothers (15.9\%) and 10 fathers $(11.5 \%)$.

There is no strong connection between successful coping and gender $(p=0.315)$.

This result seems to contradict the conclusions of the researches done so far according to which the mothers are clearly more successful in coping with deficiency. It is very probable though, that in the case of the present research those fathers took over the task of responding to the questionnaire who are active anyway in the duties concerning the child. The results referring to the fathers have also been improved by the fact that there was a father among the interviewers (he did 8 interviews, and most of them were answered by fathers) who is active in the parent group and had a positive influence on the other fathers' coping with the deficiency. This phenomenon, however, is a signal for the specialists working with the parents of disabled children: only a father can have the effect of a catalyst in reaching other fathers, in helping them in an area where the efforts of the specialists usually have not proved to be efficient enough.

- In 93.3 percent of the cases there is a father in the family beside the successfully coping mothers. The mothers belong to the group of successfully coping parents in a greater percentage even if the father does not have a supportive attitude, compared to the cases where the mothers bring up their children alone $(\mathrm{p}=0.01)$.

- If there is a healthy younger brother or sister, the family belongs to those successfully coping $(\mathrm{p}=0.04)$. In 62.2 percent of the successfully coping families there is a younger brother or sister. There is no clear and determining connection between the undefined age of a brother or sister and the successful coping,

\footnotetext{
${ }^{2}$ The questionnaire is the adapted and developed version of the questionnaire of the ELTE Sociological Institute and Post-Graduate Institute, Social Work and Welfare Policies Department (Budapest) developed in 1998 and applied for the surveying of the situation of handicapped children and their family members. In the chapter on the analysis of the family relation system the author used questions from the material of the HOME (Home Observation for the Measurement of the Environment) tests, too.
} 
although even in those cases those parents are more successful who have other children beside the disabled child. (Here we can find the cause-effect relation: are they successful in coping because a healthy child was also born, or did they dare to have another child because they had already coped with the fact of the deficiency? The latter seems to be more probable.)

- In the families where the disabled child had a share in early stage developing $(63.6 \%)$, or in pre-school age development $(68.8 \%)$ and this helped him or her, the parent belongs to those successfully coping $(\mathrm{p}=0.05)$.

- No clear connection between successful coping and the degree of deficiency could be found. The coping parents' children can be found in each type of deficiency appearing in the model.

- Coping is not influenced by the parents' education or occupation; however, in the case of the mothers, if they have higher education and they stayed home to take care of the child, in $100 \%$ they belong to those who are not successful. In the case of the unemployed and the retired coping is also more difficult. In the case of those having the occupation of 'staying home' coping is decisively influenced by the existence of the parent group, of course in a positive way $(\mathrm{p}=0.001)$.

- The existence or the absence of the power sources totally determines coping: those not referring to any kind of power source all belong to the group of people who cannot cope. The support having the strongest influence considering successful coping is the pair of 'faith + family' $(44.4 \%)$, followed by 'family' $(22.4 \%)$, and 'faith + church' (18.4\%), then 'parent group' $(8.2 \%)$.

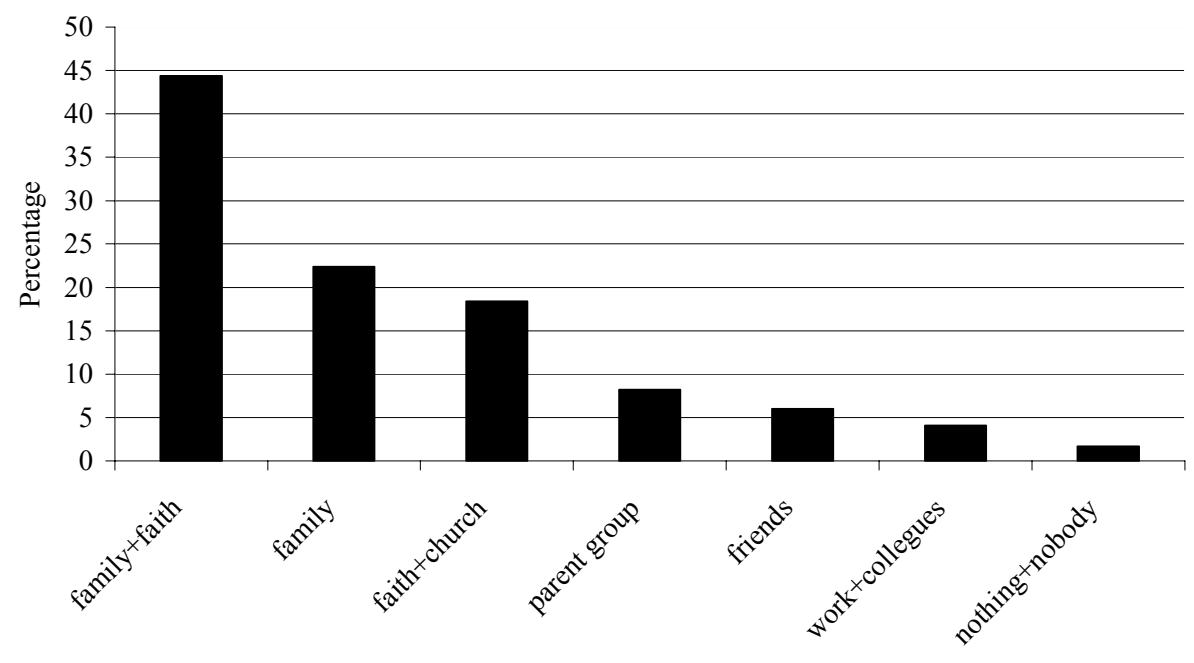

Power sources

Figure 1

What can help in everyday life? 
- The characteristics of the connection between the attitude of the immediate environment and coping (acceptance or rejection) is that the more supportive (accepting) the closest people (brothers and sisters, relatives) are, the more successful the parent is in coping. The characteristic of the connection between the burden and successful coping - based on the research model - is that the parents' coping abilities are the most sensitive to the burden of the emotional-spiritual and family relationships. The strongest connection is between the healthy brother's or sister's accepting attitude and the burden of the family $(p=0.003)$.

A 1-5 scale has been applied by the questionnaire for the acceptance of the disabled child by the environment.

Table 2

The accepted - rejected scale

\begin{tabular}{lccccc}
\hline $\begin{array}{l}\text { Evaluation of } \\
\text { being accepted }- \\
\text { rejected }\end{array}$ & $\begin{array}{c}\text { Brothers } \\
\text { and sisters } \\
(\%)\end{array}$ & $\begin{array}{c}\text { Relatives } \\
(\%)\end{array}$ & $\begin{array}{c}\text { Neighbours } \\
(\%)\end{array}$ & $\begin{array}{c}\text { Children of the } \\
\text { same age (\%) }\end{array}$ & $\begin{array}{c}\text { People in } \\
\text { general (\%) }\end{array}$ \\
\hline 5 -accepting & 71.4 & 50.8 & 43.3 & 26.3 & 21.4 \\
4 & 16.9 & 19.0 & 17.3 & 13.0 & 17.7 \\
3 & 6.3 & 14.5 & 16.8 & 20.5 & 27.0 \\
2 & 4.0 & 8.8 & 12.8 & 16.3 & 21.4 \\
$1-$ rejecting & 1.3 & 3.5 & 5.3 & 17.3 & 12.4 \\
DK/NR & $* 24.8$ & 3.5 & 4.8 & 6.8 & 5.5 \\
Altogether & $* * 100.0$ & 100.0 & 100.0 & 100.0 & 100.0 \\
Mean & 4.53 & 4.09 & 3.85 & 3.16 & 3.14 \\
\hline
\end{tabular}

*those families did not respond where there were no brothers or sisters

**only those families where there were brothers or sisters

The parents' experience is that getting further from the family the attitude is more and more distant: the less people know their handicapped fellow human beings the more prominent the 'otherness' and the stronger the rejecting attitude becomes.

- The macro level relation and the variable of coping seem to be independent except for the opinion on mass media and press $(\mathrm{p}<0.05)$. 
Table 3

What grade would you give from 1 to 10 as to the attitude of the following concerning the disabled person?

\begin{tabular}{lccccc}
\hline & Public opinion & Medical staff & $\begin{array}{c}\text { Church } \\
\text { Papers, TV, } \\
\text { radio }\end{array}$ & $\begin{array}{c}\text { Ministry responsible for } \\
\text { disabled people }\end{array}$ \\
\hline Mean & 4.45 & 6.50 & 7.53 & 5.42 & 4.71 \\
Mass media & 5.00 & 7.00 & 9.00 & 5.00 & 5.00 \\
Spread & 2.43 & 2.50 & 2.87 & 2.90 & 3.13 \\
DK/NR & 39 & 36 & 59 & 65 & 55 \\
Altogether & 361 & 364 & 341 & 335 & 345 \\
\hline
\end{tabular}

$(1=$ the lowest grade, $10=$ the highest grade $)$

Those successfully coping consider the relationship of the media with the disabled people significantly better than the others $(\mathrm{p}<0.05)$.

\subsection{Coping profile analysis}

The coping profile emerging from the research results: mothers and fathers who live in a two-parent family structure, and there is a healthy younger child in the family as well; the mother does not give up her original occupation because of the child's deficiency; their child has been successfully improved since the youngest age, they used their material resources for this reason; they have outside informal supportive connections; they are sensitive to and believe in the fact that media can be an important instrument in improving the child's state.

\subsection{Personal, family and social factors having the strongest influence in relation to deficiency}

Since the research does not work with a representative model concerning the total studied population, the interrelations and results are rather signals concerning the things that happen in the families having a disabled child and in the process of providing for the disabled person: there are listed risk factors and problems that are extant and characteristic, they reveal supportive factors or solutions that can be found.

One important conclusion of the research is that the supportive and the risk factors cannot be separated into two totally distinct and opposite groups. First of all, what is a hindering factor in one case, can mean help in another case (e.g. whether they live together with another family member or not). On the other hand, the same 
phenomenon can appear with a positive or a negative indication (e.g. degree of deficiency: the slighter the deficiency the more chance it provides, although it exists the same way and the more serious the more possible the amplifying will be). In spite of this, the levels of the ecological model can be followed through by the point of view of the risk-resilience.

Based on the results of the research, one of the most defining factors is the degree of deficiency, that is the level of deficiency. Its effects can be followed through not only in managing the present situation (kindergarten, school-options, type of teaching, right for social help), but also in light of future chances. It is characteristic that the younger ones are categorised as more serious which probably is due partly to the fact that the development potential hiding in the child cannot be predicted; it is still not obvious what the future brings, but it also has a social component, as well as a socio-political projection. The fact that those with a 'weak' financial situation are listed in the serious category shows (and this was confirmed by those working in the Diagnostics Committee) that social factors also influence the level one is put on: the well-meaning specialists want to help the families get the highest possible financial aid, so they put the child in the 'serious' degree. Two problems seem to be solved this way: the mother can look after the child further (she will be the personal, paid caretaker, she is qualified to receive the care fee), and a low but secure income source is provided for the family. This procedure raises two questions:

1. Is it right, is it good, if the system solves the social and financial need aroused by the deficiency in this way, does not this lead us back to the medical view in the long run, and does not this become the trap of deficiency?

2. If the results show that the mothers, for whom staying at home means falling out of relationships and/or falling back from their occupational status, $100 \%$ belong to those who cannot cope, is it sure that in the long run it is good for them to be the child's official caretaker, as well?

The locality type is also significant in the Rumanian nursing of disabled people in connection to both quantity and quality: moving from the municipalities to villages (they hardly know the really integrating education supported by specialists, the concept of parent group has not been heard of in the countryside). The order, however, falters in many cases, the smaller towns get behind the villages, less attention is given to the problems there: they are not part of the better supply of the municipality, nor of the better attention due to the closed ways of the village (e.g. care is better solved, there are more things to do, even if there are no jobs). This situation is probably due to the attempt to dissolve the institution-like feature of the nursing of disabled people: the village tries to manage its own problems, the needs and the problems are still transparent, and if there is some problem the child, the family is sent forward to the municipality. The town, however, belongs less to the guardianship of the municipality centre than the village, but concerning supplies and infrastructure it is far behind the latter. And of course, due to its dimensions, it is less transparent than the village. The advantages of the parents living in smaller towns are that their relation network is more extended than in the case of those living in the other two locality types, and the public opinion is 'more gracious': neither too personal (as in the village), nor too 
impersonal (as in the city). The support, found in the relation network, partly seems to balance the deficiencies of the supply system.

The effect of the financial status, supply is also manifold. The parents' education and occupational status become effective insomuch as this influences the availability of the possibilities: more income, better living conditions or better orientation in the complex procedure of getting financial aid. Surprisingly enough, better circumstances do not result in more successful coping as well. A direct, linear correlation cannot be pointed out, but an indirect connection can be: the degree of supply has a significant role in making the improving possibilities available, and this closely relates to coping. The critical turning point is whether the parent decides or not to start out on the road of improving, or whether the parent has the possibility to decide: is there information, financial opportunity, does an improving activity exist? This indirect degree of supply should be built by the supply system, especially by making informing, the improving possibilities available and by eliminating the medical attitude that maintains the biological determinacy ('it is a disease, consequently it should be cured by medication').

Based on their financial status the families of the research model are mostly proved to be poor, though the percentage of unemployment is not high (compared to the mean of population). Is this a characteristic of the model, or can it be said about the studied population, too, that deficiency means poverty regarding the family? The answer is not obvious. In the case of the very poor families the sum paid for the child's care means (more than) half of the family income. However, in the families where the mother's staying at home means the elimination of an income, and besides there are the expenses of improving, special diet, etc., deficiency definitely means financial regress, too. The families with good or medium financial status become poorer, and the very poor get an income, which however means nothing more than survival.

The parents' most important power source is the family and faith. The negative effects of the environment: prejudices, rejection of the disabled child or young person weaken this power source. The linking civilian organisations are missing from between the macro-system and the family: interest enforcing organisations, parent groups. (Maybe the church fulfils such a transitional role.) The role of the family gets overstrained in this respect, too, since there is no room for 'letting off the steam': it has to deal with the emotional burden, as well, resulting from the deficiency, and with the tension resulting from the dissatisfaction because of the system. If organisations are lacking there is no possibility for these dissatisfactions to become a positive initiative. The Ministry for the Disabled People is a far away, immanent institute that can be scored down, and which can be condemned for the lack of good changes, but the intention of 'this is for us, let's change it' does not dawn at all or hardly comes up concerning this problem. The awareness of self-determination can be born with difficulties in a country where there has been no trace of this for many decades, and it is especially difficult in an area, which was opened up for research only recently and is a debatable issue. That is why the author considers the linking organisations, institutions that know the everyday life of the handicapped, too, but they can contact the 
decision-making bodies of the macro system and they can intermediate in two directions.

Few families having adult disabled family members were included in the research model. In spite of this it is clear from the analysis that they are in an increasingly difficult situation. If the young disabled persons leave the activities provided for them by school and professional training, their possibilities strongly decrease. Most of the people responding to the questionnaire described the dynamism of coping with the deficiency as a process that can also be defined as grieving, which consists of first coping and recoveries needed again and again, preceded by the hard phases developed throughout the years. They consider the most difficult period in life, at least that is anticipated by the parents, when their own strength, health, financial situation is already deteriorating. The supply system and the helping specialists have a big responsibility in not leaving the parents alone with their children during this period of their lives, giving back the feeling of dignity and self-esteem to the affected child and/or family.

\section{References}

BÁNFALVY, Cs. (1996) 'A felnőtt értelmi fogyatékosok életminőségének jellemzőiröl’, Szociális Munka 8:2, 81-94.

Berg, M., R. JAHNSEN, K.F. FrøSLIE \& A. Hussain (2004) 'Reliability of the Pediatric Evaluation of Disability Inventory (PEDI)', Physical \& Occupational Therapy in Pediatrics $24: 3,61-77$.

BRONFENBRENNER, U. (1979) The Ecology of Human Development: Experiments by Nature and Design (Cambridge: Harvard UP).

Fraser, M. W., ed. (2004) Risk and Resilience in Childhood: An Ecological Perspective (2 ${ }^{\text {nd }}$ ed.; Washington: NASW).

LI-TSANG W.-P.C., K.-S.M. YAU \& Y. HON KONG (2001) 'Success in Parenting Children with Developmental Disabilities: Some Characteristics, Attitudes and Adaptive Coping Skills', The British Journal of Developmental Disabilities 47:2 (Jul), 61-71.

SANDERSON, W.H. \& M. CRAWLey (1982) 'Characteristics of Successful Family-Care Parents', American Journal of Mental Deficiency 86:5 (Mar), 519-25.

Singer, H.S.G. (2002) 'Suggestions for a Pragmatic Program of Research on Families and Disability', The Journal of Special Education 3, 150-56.

TAYLOR, H. (1998) 'Americans with Disabilities still Pervasively Disadvantaged on a Broad Range of Key Indicators: Huge Differences between those with and without Disabilities, in Employment, Income, Transportation, Health Care and Life Satisfaction', The Harris Poll 56, retrieved on 1 December 2008 from http://www.harrisinteractive.com/harris poll/index.asp?PID=152. 